\title{
Acknowledgement to Referees
}

(c) The Author(s) 2018

Dear Reader,

As we reach the final issue of Drugs—Real World Outcomes for 2018, we wish to reflect on another successful year's achievements, and to thank all those who have contributed their time and effort to guarantee the high quality of our content.

2018 was a successful year for Drugs—Real World Outcomes. We are delighted that the Journal was accepted for indexing in Scopus this year, to add to our indexing on PubMed.

A range of articles have been published in 2018; the most popular of these, in terms of downloads from SpringerLink, have been:

An Evaluation of "Drug Ineffective" Postmarketing Reports in Drug Safety Surveillance. Misu, T., Kortepeter, C.M., Muñoz, M.A. et al. Drugs—Real World Outcomes (2018) 5: 91. https://doi.org/10.1007/s40801-018-0131-3

Adverse Drug Events and Medication Errors in African Hospitals: A Systematic Review. Mekonnen, A.B., Alhawassi, T.M., McLachlan, A.J. et al. Drugs-Real World Outcomes (2018) 5: 1. https://doi.org/10.1007/s40801-017-0125-6

Diagnoses of Cardiovascular Disease or Substance Addiction/Abuse in US Adults Treated for ADHD with Stimulants or Atomoxetine: Is Use Consistent with Product Labeling? Fairman, K.A., Davis, L.E., Peckham, A.M. et al. Drugs-Real World Outcomes (2018) 5: 69. https://doi.org/10.1007/s40801-017-0129-2

Use of Topical Tacrolimus and Topical Pimecrolimus in Four European Countries: A Multicentre Database Cohort Study. Kuiper, J.G., van Herk-Sukel, M.P.P., Castellsague, J. et al. Drugs-Real World Outcomes (2018) 5: 109. https://doi. org/10.1007/s40801-018-0133-1

Persistence with Biological Disease-modifying Antirheumatic Drugs and Its Associated Resource Utilization and Costs.

Sruamsiri, R., Kameda, H. \& Mahlich, J. Drugs—Real World Outcomes (2018) 5: 169. https://doi.org/10.1007/s4080 1-018-0139-8

Estimating Prevalence and Healthcare Utilization for Treatment-Resistant Depression in Japan: A Retrospective Claims Database Study. Mahlich, J., Tsukazawa, S. \& Wiegand, F. Drugs-Real World Outcomes (2018) 5: 35. https://doi. org/10.1007/s40801-017-0126-5

Economic Impact in Medicaid Beneficiaries with Schizophrenia and Cardiometabolic Comorbidities Treated with OnceMonthly Paliperidone Palmitate vs. Oral Atypical Antipsychotics. Lafeuille, MH., Tandon, N., Tiggelaar, S. et al. DrugsReal World Outcomes (2018) 5: 81. https://doi.org/10.1007/s40801-018-0130-4

Recent Trends in the Practice of Procedural Sedation Under Local Anesthesia for Catheter Ablation, Gastrointestinal Endoscopy, and Endoscopic Surgery in Japan: A Retrospective Database Study in Clinical Practice from 2012 to 2015. Matsui, A., Morimoto, M., Suzuki, H. et al. Drugs-Real World Outcomes (2018) 5: 137. https://doi.org/10.1007/s4080 1-018-0136-y

Spontaneous Reporting on Adverse Events by Consumers in the United States: An Analysis of the Food and Drug Administration Adverse Event Reporting System Database. Toki, T. \& Ono, S. Drugs—Real World Outcomes (2018) 5: 117. https://doi.org/10.1007/s40801-018-0134-0

Clinical Outcomes with First-Line Chemotherapy in a Large Retrospective Study of Patients with Metastatic Pancreatic Cancer Treated in a US Community Oncology Setting. Cartwright, T.H., Parisi, M., Espirito, J.L. et al. Drugs-Real World Outcomes (2018) 5: 149. https://doi.org/10.1007/s40801-018-0137-x

We thank the authors who have contributed articles to Drugs-Real World Outcomes over the course of 2018. The skill and dedication of all authors are critical to the continued publication of the journal. The quality of published articles is also 
testament to the significant efforts of the peer reviewers, whose commitment ensures that the journal's content is held to the highest possible standard. We would like to thank the following individuals who acted as reviewers for Drugs-Real World

Outcomes in the last 12 months:

Andrew J. Armstrong, USA

Joel Bazira, Uganda

Marc Buyse, Belgium

Pia Caduff-Janosa, Sweden

Wendy Cheng, USA

Alessandro Cozzi-Lepri, UK

Cheryl Enger, USA

Anthony William Fox, UK

Alexander Hann, Germany

Amany Hassan, USA

Pedro Inacio, Finland

Chieko Nakamura Ishiguro, Japan

Yawen Jiang, USA

Pradip Kamat, USA

Mari Kihara, Japan

Tom Kovitwanichkanont, Australia

Angela Lupattelli, Norway

Yoann Madec, France

Lara Magro, Italy

Nashwa Masnoon, Australia

Omid Mehrpour, Islamic Republic of Iran

Manuel Muñoz, Spain
Patrick Musicha, Malawi

Mamoru Narukawa, Japan

Mette Noer, Denmark

Kaori Nomura, Japan

Mei-Sing Ong, USA

Alexandra Cristina Pacurariu, the Netherlands

Leàn Rolfes, the Netherlands

Ryoko Sakai, Japan

Jan Sieluk, USA

Victorita Sorodoc, Romania

Esther Helen Steveling, Switzerland

Hidekazu Suzuki, Japan

Ake Svensson, Sweden

Silia Vitoratou, UK

Ami Vyas, USA

Chi-Chuan Wang, Taiwan

Eric Weinhandl, USA

Dahlia Weitzman, Israel

Changhoon Yoo, Republic of Korea

Ruizhi Zhao, USA

In addition, we would like to thank the members of the journal's Honorary Editorial Board, who have acted as peer reviewers and authors, and have provided guidance on journal content, policy and processes:

G.C. Alexander, Johns Hopkins University, Baltimore, MD, USA

A. Beresniak, Data Mining International, Geneva, Switzerland

H. Birnbaum, Analysis Group, Inc., Boston, MA, USA

J. Bottomley, Amygdala Ltd., Letchworth Garden City, England

P. Denig, University of Groningen, Groningen, The Netherlands

J.E. Fincham, Presbyterian College School of Pharmacy, Clinton, SC, USA

B. Godman, Karolinska Institutet, Stockholm, Sweden

D. Goldsmith, Goldsmith Pharmacovigilance and Systems, New York, NY, USA

S. Karve, AbbVie, Chicago, IL, USA

N.Y. Kirson, Analysis Group, Inc., Boston, MA, USA

C. Kozma, CK Consulting Associates, St. Helena Island, SC, USA

T. Lasky, MIE Resources, Baltimore, MD, USA

A.A. Mangoni, Flinders University, Adelaide, SA, Australia

S. Mimica-Matanovic, University Hospital Osijek, Osijek, Croatia

A. Modi, Merck \& Co., Whitehouse Station, NJ, USA

P.G. Parmar, Auckland University of Technology, Auckland, New Zealand

B. Rinaldi, University of Capania Luigi Vanvitelli, Naples, Italy

J.K. Sluggett, Monash University, Parkville, VIC, Australia

K.A. Swanson, University of Oklahoma, Oklahoma City, OK, USA

J.E Ware Jr., University of Massachusetts, Worcester, MA, USA

Q. Zou, Medstar Health Research Institute, Washington, DC, USA 
We do hope that you have found the articles published throughout the year in Drugs-Real World Outcomes to be interesting and informative. We are looking forward to bringing you many high-quality and authoritative articles over the coming year.

With best wishes

Dene Peters (Editor) and Kathy Fraser (Deputy Editor)

Open Access This article is distributed under the terms of the Creative Commons Attribution-NonCommercial 4.0 International License (http:// creativecommons.org/licenses/by-nc/4.0/), which permits any noncommercial use, distribution, and reproduction in any medium, provided you give appropriate credit to the original author(s) and the source, provide a link to the Creative Commons license, and indicate if changes were made. 